\title{
Sobressemeadura de cultivares de aveia em pastagem de estrela- africana manejada com diferentes resíduos de forragem
}

\section{Overseeded of oat cultivars in grazing African star with different wastes managed forage}

\author{
Carlos Eduardo Kruger da Silva ${ }^{1 *}$; Luis Fernando Glasenapp de Menezes²; \\ Magnos Fernando Ziech²; Fernando Kuss²; Ricardo Ronsani ${ }^{3}$; \\ Ronaldo Rubens Biesek ${ }^{3}$; Bruna Boito ${ }^{4}$; Eduardo Lisbinski ${ }^{3}$
}

\begin{abstract}
Resumo
O objetivo do trabalho foi avaliar a sobressemeadura de diferentes cultivares de aveia em pastagem de estrela-africana (Cynodon nlemfuensis vr. Nlemfuensis) manejada com diferentes resíduos de forragem. Os cultivares de aveia utilizados foram aveia preta comum (Avena strigosa), aveia branca comum (Avena sativa), aveia preta cultivar IAPAR-61 (Avena strigosa cv IAPAR-61), aveia branca cultivar IAPAR-126 (Avena sativa cv IAPAR-126). A pesquisa foi realizada na Universidade Tecnológica Federal do Paraná, Câmpus Dois Vizinhos, no período de 15/05/2009 e 26/10/2009. O delineamento experimental utilizado foi o bloco ao acaso, em um esquema fatorial 4 × 3 (quatro cultivares de aveia e três resíduos de estrela africana). Foram avaliados: massa de forragem, porcentagem dos componentes estruturais da forragem, produção total, produção total de aveia e colmo, produção de estrela africana e qualidade das forragens. Não houve interação entre cultivar e resíduo de forragem para nenhuma das variáveis estudadas. A pastagem sobressemeada com a aveia branca cv. IAPAR-126 apresentou maior produção de forragem total (aveia + estrela africana) $(4.427,1$ contra $2.384,0 \mathrm{~kg}$ de MS/ha) e de aveia $(2.453,0$ contra $1.588,7$ $\mathrm{kg} \mathrm{MS} / \mathrm{ha}$ ) em comparação à aveia preta comum. A aveia preta comum apresentou maior percentual de colmo $(13,6 \%)$ em relação a aveia branca cv. IAPAR-126 (5,4 \%). A aveia branca comum apresentou maior teor de FDA no resíduo (estrela africana + aveia) em comparação a aveia branca IAPAR-126 (41,9 contra 36,3\%). Já a aveia branca comum apresentou menor teor de FDN $(49,0 \%)$ em relação à aveia branca IAPAR $126(54,9 \%)$ e a aveia preta comum $(57,0 \%)$. Em relação à proteína bruta, a aveia preta comum apresentou maior teor $(15,6 \%)$ em relação as demais.
\end{abstract}

Palavras-chave: Cynodon, FDN, FDA, proteína, IAPAR 61, IAPAR 126

\begin{abstract}
The objective of this study was to evaluate the oversown of different oat cultivars in grazing African star (Cynodon nlemfuensis vr. Nlemfuensis) managed with different forage residuals. The oat cultivars used were black oat (Avena strigosa), common oat (Avena sativa), oat IAPAR-61 (Avena strigosa IAPAR cv-61), oat IAPAR-126 (Avena sativa IAPAR cv-126). The research was conducted at Federal Technological University of Paraná, Campus Dois Vizinhos, between 05/15//2009 and 10/26/2009. The
\end{abstract}

${ }^{1}$ Discente do curso de Zootecnia e bolsista de iniciação cientifica CNPq, Universidade Tecnológica Federal do Paraná, UTFPR, Campus Dois Vizinhos, PR. E-mail: eduardokru@gmail.com

2 Profs. do Curso de Zootecnia, UTFPR, Campus Dois Vizinhos, PR. E-mail: luismenezes@utfpr.edu.br; fernandokuss@utfpr.edu. br; magnos@utfpr.edu.br

${ }^{3}$ Discente(s) do curso de Zootecnia e bolsista de iniciação cientifica CNPq, UTFPR, Campus Dois Vizinhos, PR. E-mail: ricardoronsani@hotmail.com; ronaldo_biesek@zootecnista.com.br; eduardo_lisbinski@hotmail.com

${ }^{4}$ Discente do Programa de Pós-Graduação em Zootecnia, UFPR, Campus Dois Vizinhos, PR. E-mail: bruna.boito@hotmail.com

* Autor para correspondência 
experimental design was randomized blocks, in a $4 \times 3$ factorial arrangement (four oat cultivars and three residues African star). We evaluated forage mass, percentage of the structural components of the forage, total production, total production of oats and stem production stargrass and forage quality. There was no interaction between cultivar and the forage for the variables studied. The oversown with oat cv. IAPAR-126 showed higher total forage production (oat + African star) (4427.1 versus 2384.0 $\mathrm{kg} \mathrm{DM} / \mathrm{ha}$ ) and oats (2453.0 versus $1588.7 \mathrm{~kg} \mathrm{DM} / \mathrm{ha}$ ) compared to the common oat. The black oat showed higher percentage of stem (13.6\%) compared to oat cv. IAPAR-126 (5.4\%). The common oat showed higher ADF content in the residue (African star + oats) compared to oat IAPAR-126 (41.9 versus $36.3 \%)$. Already the common oat showed lower NDF (49.0\%) compared to oats white IAPAR $126(54.9 \%)$ and black oat $(57.0 \%)$. The common oat showed a higher content of crude protein $(15.6 \%)$ compared to others cultivars.

Key words: Cynodon, NDF, ADF, protein, IAPAR 61, IAPAR 126

\section{Introdução}

A produção pecuária do Sul do Brasil é predominantemente realizada a base de pastagem. Nesse sistema há duas épocas bem distintas de produção forrageira, o verão com alta produtividade e o inverno, que necessita de um aporte de nutrientes, via rações, forragens conservadas ou pastagem cultivada para manter o nível de produtividade. Entre as espécies perenes de verão mais utilizadas estão a do gênero Cynodon destacando-se a estrela africana (Cynodon nlemfluensis) na região Sudoeste do Paraná.

Essas espécies apresentam adequada produção de forragem na época primavera-verão e severos déficits no período frio (GOMAR et. al., 2004). Prado et al. (2003) observaram ganhos de peso negativos quando utilizaram novilhos em crescimento em pastagem de Cynodon durante o período de inverno. Portanto, é necessário gerar alternativas para melhorar a produtividade e o valor nutritivo dessas áreas nesse período. Entre as mais econômicas, as que não apresentam inclusão de grãos na dieta dos animais, se destaca a associação de espécies temperadas. Rocha et al. (2007) afirmam que a sobressemeadura de aveia e azevém em pastagens perenes de estação quente consiste em uma alternativa de ajuste no fornecimento de forragem, pois permite a ocupação das áreas durante todo o ano, tornando mais eficiente a utilização de áreas pastoris.

O sucesso da sobressemeadura está relacionado à influência de uma espécie sobre a outra. Segundo
Lenzi (2003), o manejo adequado de pastagens, deve ser considerado como um fator que assegure seu pleno estabelecimento e persistência, proporcionando rendimento e qualidade para a utilização mais eficiente pelos animais. Bertolote (2009) observou maior produtividade da pastagem temperada (aveia) quando a espécie perene de verão (Capim Tanzânia) foi rebaixada a $10 \mathrm{~cm}$ em comparação a rebaixada a $30 \mathrm{~cm}$, não encontrando prejuízo na rebrota da pastagem no período de verão.

Segundo Cecato et al. (2001), o cultivo de forrageiras de inverno tem sido preconizado como uma alternativa viável para a alimentação de ruminantes. Entre as espécies recomendadas, a aveia preta (Avena strigosa Schreb) é a mais utilizada em cultivo singular para alimentação de ruminantes, na forma de pastejo, devido à sua resistência a doenças (GODOY; BATISTA, 1990), enquanto a aveia branca (Avena sativa) tem sido recomendada para a produção de grãos ou para cobertura de solo, porém, apresenta grande potencial na utilização em pastejo. Tanto a aveia preta comum quanto a aveia branca comum, apresentam ciclos produtivos precoces e um ciclo vegetativo curto, dependendo da região e das condições climáticas. Com isso, foi lançado no mercado alguns cultivares com ciclo mais longo para o melhor aproveitamento por parte dos animais, como os desenvolvidos pelo Instituto Agronômico da Paraná, IAPAR 61 - aveia preta e IAPAR 126 - aveia branca. A produção de matéria seca (MS) de aveias apresenta variação de acordo 
com a região e o cultivar utilizado, sendo que para a recomendação de seu uso deve-se primeiramente identificar quais se adaptam melhor à determinada região e ao manejo.

Sendo assim o objetivo deste trabalho foi avaliar quatro cultivares de aveia sobressemeadas em pastagem de estrela-africana manejada com diferentes resíduos de forragem.

\section{Material e Métodos}

O experimento foi conduzido de maio a outubro de 2009, na Universidade Tecnológica Federal do
Paraná (UTFPR) - campus Dois Vizinhos - PR, localizada na região fisiograficamente chamada de terceiro planalto paranaense. Possui altitude de $520 \mathrm{~m}$, latitude de $25^{\circ} 44^{\prime \prime}$ Sul e longitude de $53^{\circ} 04^{\prime \prime}$ Oeste, sendo o clima do tipo subtropical úmido mesotérmico (Cfa), segundo a classificação de Köppen (OMETTO, 1981). O solo é classificado como Latossolo vermelho distroférrico de textura argilosa. A temperatura e precipitação média do período experimental, conforme dados da Estação Meteorológica da UTFPR, localizada próximo a área experimental, foram de $16{ }^{\circ} \mathrm{C}$ e $196,1 \mathrm{~mm}$. (Figura 1). respectivamente.

Figura 1. Dados médios de precipitação mensal, temperatura máxima (Temp. Max.) e temperatura mínima (Temp. Min.) no período de maio a outubro de 2009.

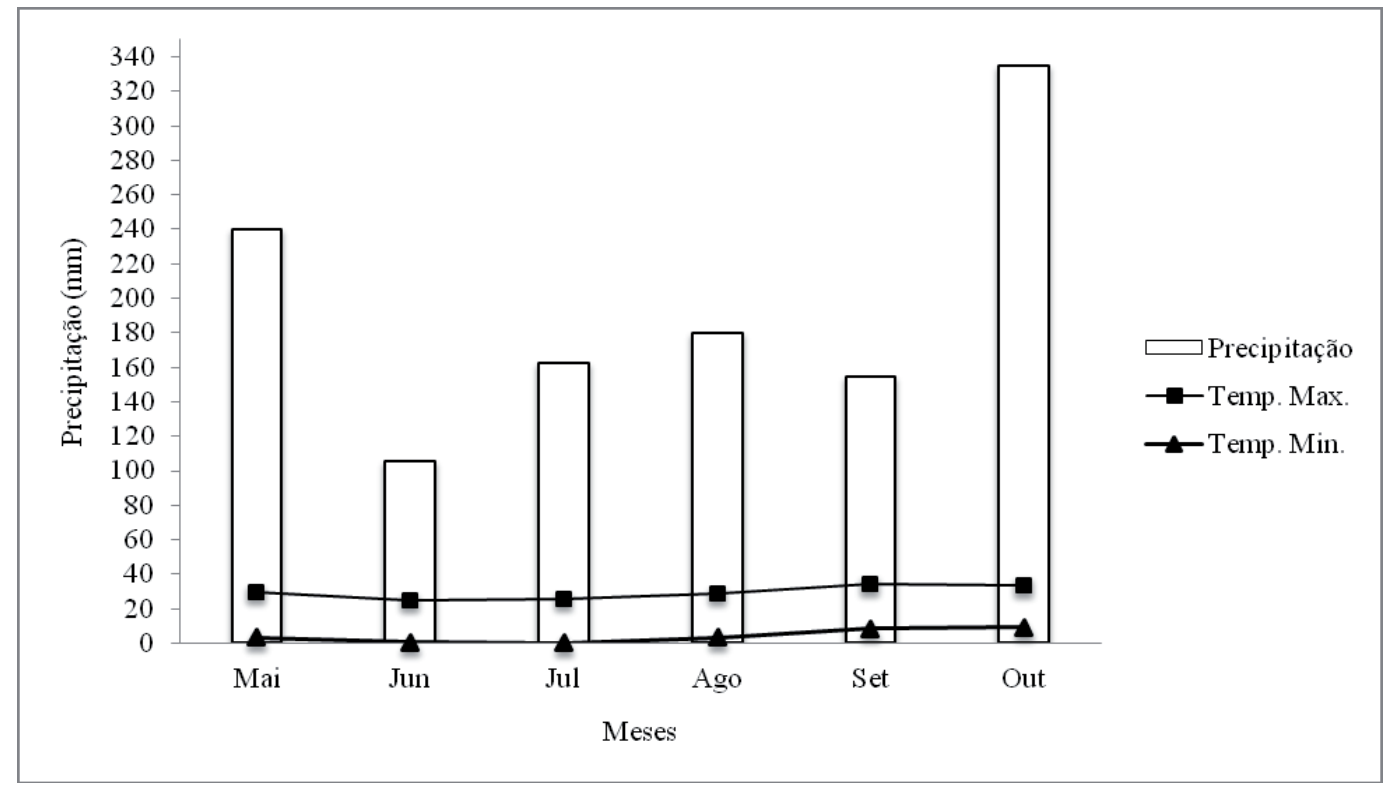

Fonte: INMET (2010).

Aárea experimental se encontra nas dependências da Unidade de Ensino e Pesquisa (UEP) de Bovinocultura de Leite, onde a pastagem de estrela-africana (Cynodon nlenfuensis, Vanderyst) está estabelecida. No final do verão a pastagem foi roçada com roçadeira para que apresentasse resíduos de forragem de 2500; 3500 e $4500 \mathrm{~kg} / \mathrm{ha}$ MS o que representou alturas de 5; 13,5 e $19 \mathrm{~cm}$, após o manejo os resíduos reais ficaram em 2640; 3520 e $4480 \mathrm{~kg} /$ ha de MS. A área, foi subdividida em 48 parcelas de $20 \mathrm{~m}^{2}$. Para cada resíduo foram sobressemeadas quatro cultivares de aveia com 4 repetições cada.

A sobressemeadura de aveia foi realizada no dia 15/05/2009 com auxilio de semeadoura de plantio 
direto, utilizando $60 \mathrm{~kg} / \mathrm{ha}$ para aveia preta e $40 \mathrm{~kg} /$ ha para aveia branca de sementes puras e viáveis. A adubação de base foi $100 \mathrm{~kg} / \mathrm{ha}$ de adubo NPK da fórmula 05-20-20, com adubação nitrogenada de 50 $\mathrm{kg} /$ ha de uréia, usada em cobertura, após cada corte. Essas quantidades foram posteriormente corrigidas para o tamanho da parcela.

As parcelas foram manejadas para simular o pastejo rotativo, ou seja, à medida que a pastagem atingisse $30 \mathrm{~cm}$ de altura a parcela era rebaixada a $10 \mathrm{~cm}$ com auxílio de roçadeira manual para a determinação da produção de forragem (MF) no período. A forragem proveniente das amostras cortadas foi homogeneizada e duas amostras foram retiradas para estimativa da composição botânica da pastagem e outra para determinação do teor de MS. Na amostra para determinação da composição botânica, cada espécie (estrela-africana e aveia) foi separada nos componentes estruturais folha, colmo e material senescente. A produção total de MS foi calculada pelo somatório das produções dos períodos (taxa de acúmulo diário x número de dias do período) mais a massa de forragem inicial.

As amostras foram secas em estufa de ventilação forçada a $55^{\circ} \mathrm{C}$ para estimativa do percentual de cada componente, com base na MS. Após secas as amostra foram trituradas em moinho tipo Willey com peneira de $1 \mathrm{~mm}$ de diâmetro para análise das seguintes variáveis: matéria seca total (MS), proteína bruta $(\mathrm{PB})$, fibra detergente neutro $(\mathrm{FDN})$ e fibra detergente ácido (FDA).

O delineamento experimental utilizado foi blocos ao acaso, em esquema fatorial $3 \times 4$ (3 resíduos de forragem da estrela africana $\mathrm{x} 4$ cultivares de aveia), com 4 repetições. Os resultados foram submetidos à análise de variância e as médias que apresentaram interação significativa ou efeito para resíduo de estrela-africana sofreram análise de regressão. Aquelas que apresentarem efeito apenas para o cultivar de aveia foram comparadas através do teste ' $\mathrm{t}$ '.

\section{Resultados e Discussão}

Não houve interação entre cultivares de aveia e resíduo de forragem para o intervalo entre cortes e produção de MS, tanto total como dos componentes da pastagem (Tabela 1). O resíduo de forragem de estrela africana anterior à semeadura da pastagem de aveia não afetou $(\mathrm{P}>0,05)$ o intervalo entre cortes e a produção de matéria MS, de aveia e de capim estrela africana (Cynodon nlemfuensis vr. Nlemfuensis). Esperava-se que o maior resíduo da pastagem tropical interferisse negativamente no desenvolvimento da aveia. Existem poucos trabalhos avaliando a altura ideal de rebaixamento da espécie tropical sobre a produtividade da espécie sobressemeada. Moreira et al. (2006) utilizaram rebaixamento para $5 \mathrm{~cm}$ de altura e Rodrigues et al. (2006) entre 10 e $20 \mathrm{~cm}$ em espécies do genêro Cynodon, porém, a influência da altura de rebaixamento sobre as plantas sobressemeadas não são mencionadas. Bertolote (2009) trabalhando com sobressemeadura de aveia em Capim Tanzânia rebaixado a 10 ou $30 \mathrm{~cm}$, observou maior produção de Capim Tanzânia e produção de forragem total quando rebaixou a Tanzânia a $10 \mathrm{~cm}$. No entanto, estes autores não observaram efeito na altura de rebaixamento sobre a produção da espécie de clima temperado.

Um fator que pode ter contribuído para que não houvesse efeito da altura de rebaixamento sobre o desenvolvimento da espécie temperada foi a ocorrências de geadas cumulativas nos meses de junho e julho antes do primeiro corte (Figura 1). Observa-se que no início da avaliação a participação da estrela africana era praticamente nula (Figura 2), havendo um crescimento na participação da gramínea tropical com o tempo. 
Tabela 1. Médias e erros-padrão da produtividade de componentes da pastagem de estrela africana rebaixada com diferentes resíduos de forragem e sobressemeada com diferentes cultivares de aveia.

\begin{tabular}{|c|c|c|c|c|c|}
\hline \multirow{2}{*}{$\begin{array}{c}\text { Resíduo de } \\
\text { Estrela Africana } \\
\left(\mathrm{kg} \mathrm{MS} \mathrm{ha-1}^{-1}\right)\end{array}$} & \multicolumn{2}{|c|}{ AVEIA PRETA } & \multicolumn{2}{|c|}{ AVEIA BRANCA } & \multirow{2}{*}{ MÉDIA } \\
\hline & COMUM & IAPAR -61 & COMUM & IAPAR -126 & \\
\hline \multicolumn{6}{|c|}{ Intervalo entre Cortes (dias) } \\
\hline 2640 & $43,4 \pm 5,7$ & $53,2 \pm 6,6$ & $42,8 \pm 5,7$ & $50,1 \pm 5,9$ & $44,7 \pm 2,9$ \\
\hline 3520 & $45,2 \pm 5,7$ & $42,3 \pm 5,7$ & $48,2 \pm 6,2$ & $43,1 \pm 5,7$ & $47,4 \pm 3,0$ \\
\hline 4480 & $41,2 \pm 6,2$ & $49,3 \pm 5,9$ & $53,4 \pm 8,1$ & $48,7 \pm 6,2$ & $48,1 \pm 3,3$ \\
\hline MÉDIA & $43,3 \pm 3,4$ & $48,2 \pm 3,5$ & $48,1 \pm 3,9$ & $47,3 \pm 3,4$ & -- \\
\hline \multicolumn{6}{|c|}{ Produção Total ( kg de MS/ha) } \\
\hline 2640 & $2315,1 \pm 851,8$ & $3242,1 \pm 942,4$ & $3818,3 \pm 815,4$ & $5125,1 \pm 815,4$ & $3118,5 \pm 417,8$ \\
\hline 3520 & $2357,7 \pm 815,4$ & $2786,3 \pm 815,4$ & $3117,4 \pm 894,2$ & $4212,6 \pm 815,4$ & $3625,2 \pm 429,0$ \\
\hline 4480 & $2479,2 \pm 893,5$ & $3599,3 \pm 851,8$ & $3917,9 \pm 1153,9$ & $3943,4 \pm 894,2$ & $3485,0 \pm 477,7$ \\
\hline MÉDIA* & $2384,0 \pm 493,1^{\mathrm{b}}$ & $3209,2 \pm 503,3^{\mathrm{ab}}$ & $3617,9 \pm 557,0^{\mathrm{ab}}$ & $4427,1 \pm 486,4^{\mathrm{a}}$ & -- \\
\hline \multicolumn{6}{|c|}{ Produção Aveia (kg de MS/ha) } \\
\hline 2640 & $1146,2 \pm 338,1$ & $1888,3 \pm 374,1$ & $1929,8 \pm 323,7$ & $2918,0 \pm 323,7$ & $1971,4 \pm 165,8$ \\
\hline 3520 & $1873,8 \pm 323,7$ & $1867,5 \pm 323,7$ & $1614,3 \pm 355,0$ & $2530,0 \pm 323,7$ & $1970,6 \pm 170,3$ \\
\hline 4480 & $1746,1 \pm 353,7$ & $1741,7 \pm 338,1$ & $1746,7 \pm 458,0$ & $1913,2 \pm 355,0$ & $1786,9 \pm 189,6$ \\
\hline MÉDIA* & $1588,7 \pm 195,7^{\mathrm{b}}$ & $1832,5 \pm 199,8^{\text {ab }}$ & $1763,6 \pm 221,1^{\mathrm{ab}}$ & $2453,0 \pm 193,0^{\mathrm{a}}$ & -- \\
\hline \multicolumn{6}{|c|}{ Produção de capim Estrela africana (kg de MS/ha) } \\
\hline 2640 & $1115,9 \pm 702,5$ & $793,1 \pm 844,5$ & $2426,8 \pm 702,2$ & $635,0 \pm 763,4$ & $1242,7 \pm 377,9$ \\
\hline 3520 & $1150,5 \pm 730,8$ & $587,3 \pm 730,8$ & $1117,4 \pm 801,6$ & $343,5 \pm 702,2$ & $799,7 \pm 371,1$ \\
\hline 4480 & $1264,3 \pm 801,6$ & $1051,5 \pm 763,4$ & $1480,4 \pm 1034,1$ & $1643,4 \pm 763,8$ & $1359,9 \pm 423,9$ \\
\hline MÉDIA & $1176,9 \pm 430,5$ & $810,6 \pm 451,0$ & $1674,9 \pm 494,6$ & $873,9 \pm 429,3$ & -- \\
\hline
\end{tabular}

*médias seguidas por letras distintas na linha diferem entre si $(\mathrm{P}<0,05)$ pelo teste Tukey.

Fonte: Elaboração dos autores.

Figura 2. Participação de aveia e capim estrela africana de acordo com o corte avaliado ao decorrer do período experimental.

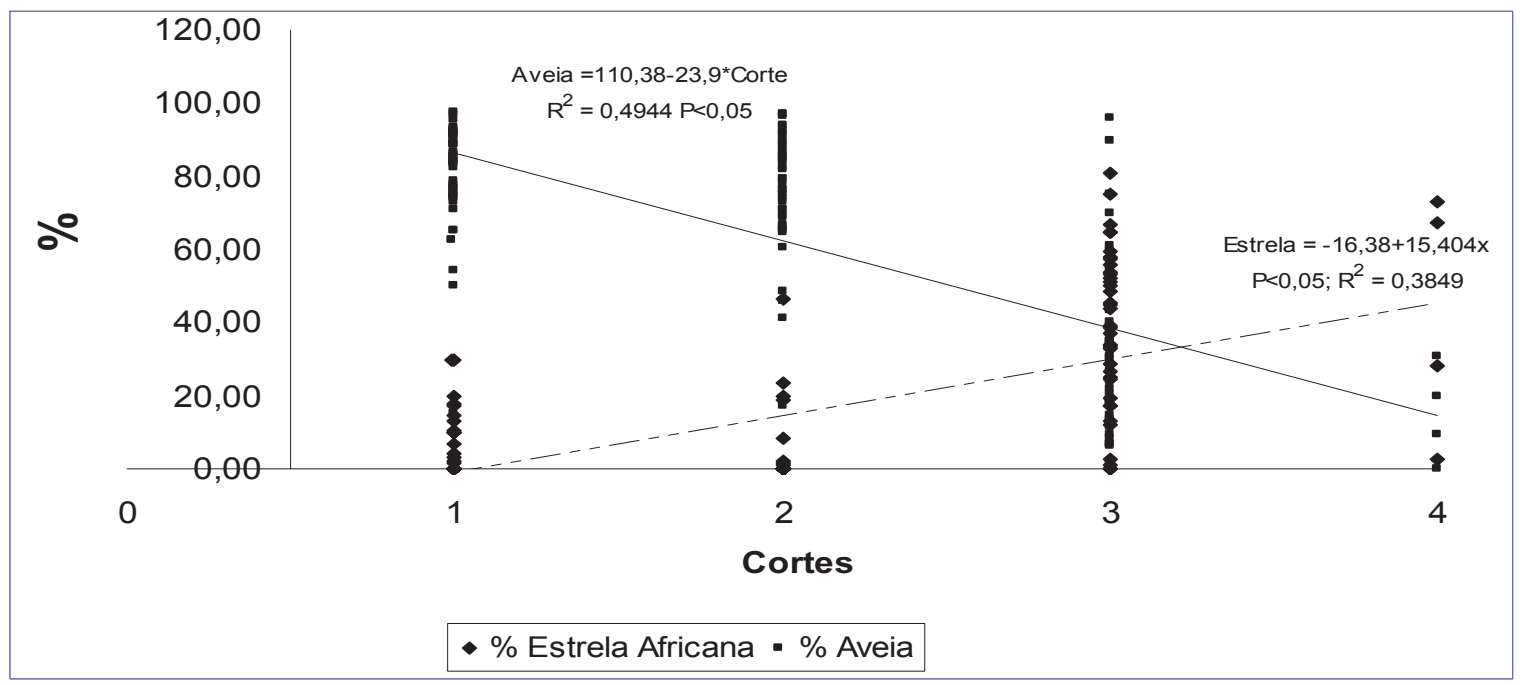

Fonte: Elaboração dos autores. 
A pastagem sobressemeada com a aveia branca cv. IAPAR-126 apresentou maior produção de forragem total e de aveia em comparação à aveia preta comum, enquanto que as aveias branca comum e preta cv. IAPAR-61 não diferiram das demais. Bortolini, Moraes e Carvalho (2005) já demonstrava a alta aptidão da aveia branca na produção animal, sendo uma boa alternativa na integração lavoura-pecuária. Del Duca et al. (1999), comparando a aveia branca UPF 14 e aveia preta comum, e Fontaneli et al. (2009), estudando as aveias preta IPFA 9909 e Agro Zebu comparadas a aveia branca UPF 18, não observaram diferença na produtividade total entre as aveias pretas e brancas, no cultivo extreme. Segundo Noro et al. (2003), a cultivar de aveia preta IAPAR 61 é mais produtiva em relação a aveia preta "comum", devido, principalmente, ao seu ciclo mais longo. No entanto, no presente estudo a estrela africana aumentou sua participação no terceiro e quarto corte (Figura 2), o que provavelmente prejudicou o desenvolvimento da cultivar de ciclo mais longo, uma vez que não havia mais participação de nenhum dos cultivares de aveia no mês de outubro. Macari et al. (2006) também não observaram diferença entre aveia preta comum e a IAPAR 61 em consórcio com o azevém.

Observa-se que os resultados médios encontrados no presente trabalho são inferiores aos encontrados em outros trabalhos que estudaram a aveia no cultivo singular. A produtividade destes cultivares, em cultivo extreme, variou na literatura, em média de 3000 a $12000 \mathrm{~kg}$ de MS/ha (PRIMAVESI et al., 2004; BORTOLINI; MORAES; CARVALHO, 2005; FEROLLA et al., 2007; PIN et al., 2011). Essa diferença deve-se a competitividade entre as espécies temperada e tropical. A estrela africana se caracteriza por ser uma espécie de alto crescimento e agressiva, além disso, a região onde se realizou o trabalho (Sudoeste do Paraná) apresenta clima favorável para o crescimento precoce (início da primavera) dessa espécie (Figura 1). Observase que o intervalo entre cortes foi de 46,78 dias, em média, superior aos 31 dias observados por Olivo et al. (2010), quando trabalharam com a sobressemeadura de azevém em Coast-cross, e por Pereira et al. (2008), quando trabalharam com sobressemeadura de aveia e azevém em Coastcross. No entanto, esses dois autores trabalharam no Rio Grande do Sul, onde o inverno é mais rigoroso, inibindo, assim, o crescimento precoce da espécie tropical. Além disso, o Coast-cross, apesar de ser uma espécie do gênero Cynodon como a Estrelaafricana, é menos agressiva e com crescimento mais lento, permitindo maior desenvolvimento da espécie temperada.

Apesar das características de produtividade serem baixas em relação àa literatura que trabalhou com cultivo extreme, a técnica apresentou bom resultados, uma vez que essas áreas normalmente não são utilizados pelos produtores durante o inverno.

O resíduo da espécie tropical pré-semeadura da pastagem temperada não interferiu na composição botânica da pastagem (Tabela 2). Observa-se que as cultivares apresentaram diferenças apenas na participação do colmo. A aveia branca IAPAR 126 e a aveia preta IAPAR 61 apresentaram menor participação de colmo em sua estrutura em relação à aveia preta comum. Essa diferença pode explicar em parte a menor produtividade deste cultivar (Tabela 1), uma vez que o alongamento do colmo representa um ciclo de desenvolvimento mais acelerado e, conseqüentemente, queda na produção pelo florescimento mais precoce. Meinerz et al. (2011) comparando a produção e o valor nutritivo da forragem de genótipos de cereais de inverno obtiveram percentagens de colmo mais elevado em aveia preta comum $(28,5 \%)$ comparada com o genótipo de aveia branca UPF-18 (21,2\%) valores semelhantes aos encontrados no presente estudo, essa ocorrência deve-se pois a aveia preta possui um ciclo vegetativo menor e conseqüentemente a percentagem de colmo tende a ser maior. Rocha et al. (2007) observaram que a participação média das espécies temperadas (aveia e azevém) na pastagem sobressemeada foi de $66,6 \%$ e a da Coastcross $24 \%$, valores semelhantes ao observado no presente estudo. 
Tabela 2. Médias e erros-padrão para a composição botânica da pastagem de estrela-africana rebaixada com diferentes resíduos de forragem, sobressemeada com diferentes cultivares de aveia.

\begin{tabular}{|c|c|c|c|c|c|}
\hline \multirow{2}{*}{$\begin{array}{c}\text { Resíduo } \\
\text { Estrela Africana } \\
\left(\mathrm{kg} \mathrm{MS} \mathrm{ha}^{-1}\right)\end{array}$} & \multicolumn{2}{|c|}{ AVEIA PRETA } & \multicolumn{2}{|c|}{ AVEIA BRANCA } & \multirow{2}{*}{ MÉDIA } \\
\hline & COMUM & IAPAR -61 & COMUM & IAPAR -126 & \\
\hline \multicolumn{6}{|c|}{ Folhas de aveia (\%) } \\
\hline 2640 & $55,0 \pm 8,5$ & $62,9 \pm 9,8$ & $65,1 \pm 8,5$ & $56,8 \pm 8,9$ & $68,9 \pm 4,3$ \\
\hline 3520 & $59,8 \pm 8,5$ & $71,5 \pm 8,5$ & $69,3 \pm 9,3$ & $74,8 \pm 8,5$ & $60,4 \pm 4,5$ \\
\hline 4480 & $59,2 \pm 9,3$ & $56,8 \pm 8,9$ & $62,5 \pm 12,1$ & $70,0 \pm 9,3$ & $61,4 \pm 5,0$ \\
\hline MÉDIA & $57,6 \pm 5,1$ & $63,2 \pm 5,2$ & $65,6 \pm 5,8$ & $67,2 \pm 5,1$ & - \\
\hline \multicolumn{6}{|c|}{ Colmos de aveia $(\%)$} \\
\hline 2640 & $12,8 \pm 2,7$ & $13,1 \pm 3,1$ & $10,7 \pm 2,7$ & $7,3 \pm 2,8$ & $9,3 \pm 1,4$ \\
\hline 3520 & $12,4 \pm 2,7$ & $6,7 \pm 2,7$ & $11,6 \pm 3,0$ & $6,4 \pm 2,7$ & $11,0 \pm 1,4$ \\
\hline 4480 & $15,5 \pm 3,0$ & $6,8 \pm 2,8$ & $6,1 \pm 3,8$ & $2,4 \pm 3,0$ & $7,6 \pm 1,6$ \\
\hline *MÉDIA & $13,6 \pm 1,6 \mathrm{a}$ & $8,7 \pm 1,6 \mathrm{~b}$ & $9,5 \pm 1,8 \mathrm{ab}$ & $5,4 \pm 1,6 \mathrm{~b}$ & - \\
\hline \multicolumn{6}{|c|}{ Capim Estrela africana (\%) } \\
\hline 2640 & $14,5 \pm 6,2$ & $10,3 \pm 7,2$ & $13,6 \pm 6,2$ & $14,7 \pm 6,5$ & $13,3 \pm 3,3$ \\
\hline 3520 & $18,3 \pm 6,2$ & $11,7 \pm 6,2$ & $12,0 \pm 6,8$ & $8,4 \pm 6,2$ & $12,6 \pm 3,2$ \\
\hline 4480 & $17,1 \pm 6,8$ & $19,6 \pm 6,5$ & $17,7 \pm 8,8$ & $8,0 \pm 6,8$ & $15,6 \pm 3,7$ \\
\hline MÉDIA & $16,7 \pm 3,7$ & $13,9 \pm 3,8$ & $14,4 \pm 4,3$ & $10,4 \pm 3,8$ & - \\
\hline \multicolumn{6}{|c|}{ Outros e material morto(\%) } \\
\hline 2640 & $18,2 \pm 3,7$ & $13,5 \pm 4,5$ & $12,1 \pm 3,7$ & $21,0 \pm 4,1$ & $16,2 \pm 2,0$ \\
\hline 3520 & $9,35 \pm 3,9$ & $9,9 \pm 3,9$ & $7,0 \pm 4,3$ & $11,3 \pm 3,7$ & $9,4 \pm 1,9$ \\
\hline 4480 & $11,1 \pm 4,3$ & $17,0 \pm 4,1$ & $13,4 \pm 5,5$ & $18,6 \pm 4,1$ & $15,0 \pm 2,2$ \\
\hline MÉDIA & $12,9 \pm 2,3$ & $13,5 \pm 2,4$ & $10,8 \pm 2,6$ & $17,0 \pm 2,3$ & - \\
\hline
\end{tabular}

*médias seguidas por letras distintas na linha diferem entre si $(\mathrm{P}<0,05)$ pelo teste Tukey.

Fonte: Elaboração dos autores.

A qualidade bromatológica da pastagem (Tabela 3) e dos cultivares da aveia (Tabela 4) não foi influenciada pelo resíduo da pastagem tropical présemeadura da pastagem temperada. Essas ausências de diferenças devem-se a baixa participação da pastagem tropical (Tabela 2), uma vez que a amostragem ocorreu a $10 \mathrm{~cm}$ de altura.

Observa-se que os valores nutricionais são mais favoráveis quando foi analisado apenas as cultivares de aveia (Tabela 4) em comparação aos valores encontrados em toda amostra (Tabela 3). Isso demonstra que a sobressemeadura de pastagens tropicais com aveia eleva o valor nutritivo de áreas com pastagem tropical no período de inverno.
As pastagens apresentaram bons valores nutritivos, segundo Noller, Nascimento Junior e Queiroz (1996), forragens com teores de FDA próximos de $30 \%$ serão consumidas em altos níveis, enquanto aquelas com teores de FDA acima de $40 \%$ serão consumidas em baixos níveis. Observa-se que na média todas as pastagens apresentaram valores abaixo de $40 \%$. Apenas a pastagem que apresentava a aveia branca comum apresentou valores superiores a 40\% (Tabela 3). No entanto, isso não se deveu a cultivar utilizada, uma vez que quando foi analisada apenas as espécies de aveia, não houve diferença para as cultivares para o teor de FDA (Tabela 4). Essa superioridade deve-se, portanto, pela maior participação, mesmo que numérica, da estrela africana nesse consórcio (Tabela 2). 
Tabela 3. Médias e erros-padrão para a qualidade bromatológica da pastagem (aveia +estrela africana), rebaixadas com diferentes resíduos e sobressemeadas com diferentes cultivares de aveia.

\begin{tabular}{|c|c|c|c|c|c|}
\hline \multirow{2}{*}{$\begin{array}{c}\text { Resíduo } \\
\text { Estrela Africana } \\
\left(\mathrm{kg} \mathrm{MS} \mathrm{ha}{ }^{-1}\right.\end{array}$} & \multicolumn{2}{|c|}{ AVEIA PRETA } & \multicolumn{2}{|c|}{ AVEIA BRANCA } & \multirow{2}{*}{ MÉDIA } \\
\hline & COMUM & IAPAR -61 & COMUM & IAPAR - 126 & \\
\hline \multicolumn{6}{|c|}{ FDA(\%) } \\
\hline 2640 & $40,4 \pm 2,8$ & $36,9 \pm 3,3$ & $42,0 \pm 3,3$ & $30,6 \pm 3,3$ & $39,2 \pm 1,6$ \\
\hline 3520 & $40,2 \pm 3,3$ & $37,1 \pm 2,8$ & $39,9 \pm 3,3$ & $30,0 \pm 3,3$ & $36,8 \pm 1,5$ \\
\hline 4480 & $38,0 \pm 2,8$ & $37,2 \pm 3,3$ & $43,6 \pm 3,3$ & $41,5 \pm 2,8$ & $40,1 \pm 1,5$ \\
\hline MÉDIA & $39,5 \pm 1,7^{\mathrm{ab}}$ & $37,0 \pm 1,8^{\mathrm{ab}}$ & $41,9 \pm 1,9^{\text {a }}$ & $36,3 \pm 1,8^{\mathrm{b}}$ & - \\
\hline \multicolumn{6}{|c|}{ FDN $(\%)$} \\
\hline 2640 & $59,1 \pm 5,9$ & $58,3 \pm 6,8$ & $57,2 \pm 6,8$ & $63,2 \pm 6,8$ & $58,9 \pm 3,3$ \\
\hline 3520 & $66,0 \pm 6,8$ & $62,3 \pm 5,9$ & $57,2 \pm 6,8$ & $61,2 \pm 6,8$ & $62,3 \pm 3,3$ \\
\hline 4480 & $60,9 \pm 5,9$ & $57,1 \pm 6,8$ & $57,6 \pm 6,8$ & $67,6 \pm 5,9$ & $60,8 \pm 3,2$ \\
\hline MÉDIA & $62,0 \pm 3,6$ & $59,3 \pm 3,8$ & $57,4 \pm 3,9$ & $64,0 \pm 3,8$ & - \\
\hline \multicolumn{6}{|c|}{ PROTEINA BRUTA $(\%)$} \\
\hline 2640 & $15,8 \pm 1,1$ & $13,6 \pm 1,1$ & $12,9 \pm 1,2$ & $12,5 \pm 1,2$ & $13,7 \pm 0,6$ \\
\hline 3520 & $13,3 \pm 1,1$ & $13,2 \pm 1,1$ & $14,4 \pm 1,2$ & $14,7 \pm 1,2$ & $14,0 \pm 0,6$ \\
\hline 4480 & $13,3 \pm 1,1$ & $11,6 \pm 1,2$ & $15,0 \pm 1,2$ & $11,1 \pm 1,1$ & $12,8 \pm 0,6$ \\
\hline MÉDIA & $14,3 \pm 0,68$ & $12,8 \pm 0,71$ & $14,1 \pm 0,74$ & $12,7 \pm 0,71$ & - \\
\hline
\end{tabular}

médias seguidas por letras distintas na linha diferem entre si $(\mathrm{P}<0,05)$ pelo teste Tukey.

Fonte: Elaboração dos autores.

Tabela 4. Médias e erros-padrão da composição bromatológica das plantas de cultivares de aveia sobressemeadas em pastagem de estrela africana rebaixadas com diferentes resíduos.

\begin{tabular}{|c|c|c|c|c|c|}
\hline \multirow{2}{*}{$\begin{array}{c}\text { Resíduo } \\
\text { Estrela Africana } \\
\left(\mathrm{kg} \mathrm{MS} \mathrm{ha-1)}^{-1}\right.\end{array}$} & \multicolumn{2}{|c|}{ AVEIA PRETA } & \multicolumn{2}{|c|}{ AVEIA BRANCA } & \multirow{2}{*}{ MÉDIA } \\
\hline & COMUM & IAPAR -61 & COMUM & IAPAR -126 & \\
\hline \multicolumn{6}{|c|}{ FDA $(\%)$} \\
\hline 2640 & $36,9 \pm 3,7$ & $33,6 \pm 3,2$ & $29,8 \pm 3,7$ & $34,0 \pm 3,7$ & $33,5 \pm 1,8$ \\
\hline 3520 & $39,7 \pm 4,6$ & $37,1 \pm 3,2$ & $36,1 \pm 3,7$ & $40,5 \pm 3,7$ & $38,3 \pm 1,9$ \\
\hline 4480 & $28,7 \pm 4,6$ & $33,4 \pm 4,6$ & $36,1 \pm 6,5$ & $35,6 \pm 3.7$ & $33,4 \pm 2,5$ \\
\hline MÉDIA & $36,7 \pm 2,1$ & $34,7 \pm 2,1$ & $34,0 \pm 2,8$ & $35,0 \pm 2,5$ & - \\
\hline \multicolumn{6}{|c|}{ FDN $(\%)$} \\
\hline 2640 & $55,8 \pm 4,3$ & $58,4 \pm 3,7$ & $47,3 \pm 4,3$ & $58,4 \pm 4,3$ & $55,0 \pm 2,1$ \\
\hline 3520 & $56,6 \pm 5,3$ & $56,5 \pm 3,7$ & $49,4 \pm 4,3$ & $53,5 \pm 4,3$ & $54,0 \pm 2,2$ \\
\hline 4480 & $58,5 \pm 5,3$ & $49,4 \pm 5,3$ & $50,2 \pm 7,5$ & $52,7 \pm 4,3$ & $52,7 \pm 2,8$ \\
\hline MÉDIA & $57,0 \pm 2,8^{\mathrm{a}}$ & $54,8 \pm 3,2^{\mathrm{ab}}$ & $49,0 \pm 2,8^{\mathrm{b}}$ & $54,9 \pm 2,5^{\mathrm{a}}$ & - \\
\hline \multicolumn{6}{|c|}{ PROTEINA BRUTA $(\%)$} \\
\hline 2640 & $13,1 \pm 1,6$ & $13,3 \pm 1,4$ & $12,9 \pm 1,6$ & $14,4 \pm 1,6$ & $13,4 \pm 0,8$ \\
\hline 3520 & $17,3 \pm 2,0$ & $13,2 \pm 1,4$ & $12,6 \pm 1,6$ & $11,5 \pm 1,6$ & $13,7 \pm 0,8$ \\
\hline 4480 & $16,3 \pm 2,0$ & $13,8 \pm 2,0$ & $14,8 \pm 2,8$ & $14,9 \pm 1,6$ & $14,9 \pm 1,1$ \\
\hline MÉDIA & $15,6 \pm 1,1^{\mathrm{a}}$ & $13,4 \pm 0,9^{\mathrm{b}}$ & $13,4 \pm 1,3^{\mathrm{b}}$ & $13,6 \pm 0,9^{b}$ & - \\
\hline
\end{tabular}

médias seguidas por letras distintas na linha diferem entre si $(\mathrm{P}<0,05)$ pelo teste Tukey.

Fonte: Elaboração dos autores. 
As plantas de aveia preta comum e a aveia branca IPR 126 apresentaram maiores teores de FDN em relação à aveia branca comum. Esse maior teor de FDN da aveia preta comum pode ser explicado pela maior participação de colmo na planta (Tabela 2). A FDN é um componente da parede celular e tem alta participação em estruturas de sustentação da planta, como é o caso do colmo. Os resultados deste estudo confirmam os obtidos por Kirchner et al. (2010) que avaliaram o desempenho de forrageiras hibernais sob distintos níveis de luminosidade, enquanto Fontaneli et al. (2009) obtiveram valores de 50\% de FDN avaliando aveia branca UPF 18 e FDN de 46,1\% para aveia branca. Moreira et al. (2006) observaram valores médios de 59\% no teor de FDN em plantas de aveia sobressemeadas em capim Tifton. Já Rocha et al. (2007) encontraram valores entre 45 e $50 \%$ de FDN, dependendo da época avaliada.

O teor de proteína bruta foi superior na aveia preta comum em comparação com os demais cultivares. Fontaneli et al. (2009) comparando duas cultivares melhoradas de aveia preta (IPFA 99009 e Agro Zebu) e uma de aveia branca (UPF 18) observaram maior teor de PB para as cultivares de aveia preta. Esse fato pode estar associado ao fato de que, quando uma determinada linhagem produz mais matéria seca, por efeito de diluição, a quantidade de nitrogênio na MS é menor (COSTA, 1990).

\section{Conclusões}

O resíduo de forragem de estrela africana no momento da sobressemeadura de aveia não interfere na produtividade e na qualidade da pastagem durante o inverno.

A aveia branca IAPAR 126 apresenta melhor produtividade e estrutura (menor percentagem de colmo) em relação à aveia preta comum. Por outro lado, a aveia preta comum apresentou maior teor de proteína bruta. A aveia preta IAPAR 61 e branca comum tiveram desempenho intermediário quando sobressemeadas em pastagem de estrela africana.

\section{Referências}

BERTOLOTE, L. E. M. Sobressemeadura de forrageiras de clima temperado em pastagens tropicais. 2009. Dissertação (Mestrado em Zootecnia) - Universidade Estadual Paulista. Faculdade de Medicina Veterinária e Zootecnia, Botucatu.

BORTOlini, P. C.; MORAES, A.; CARVAlHO, P. C. Produção de forragem e de grãos de aveia branca sob pastejo. Revista Brasileira de Zootecnia, Viçosa, MG, v. 34, n. 6, p. 2192-2199, 2005. Suplemento.

CECATO, U.; RÊGO, F. C. A.; GOMES, J. A. N.; CANTO, M. W.; JOBIM, C. C.; CONEGLIAN, S.; MOREIRA, F. B. Produção e composição química em cultivares e linhagens de aveia (Avenna spp.). Acta Scientiarum, Maringá, v. 23, n. 4, p. 775-780, 2001.

COSTA, C. Estudo da estrutura da vegetação de dois cultivares de Panicum maximum Jacq. (Colonião e Tobiatã). submetidos a diferentes tipos de manejo. 1990. (Doctoral Thesis in Animal Production) - Faculdade de Ciências Agrária e Veterinárias. Universidade Estadual Paulista, Jaboticabal.

DEL DUCA, L. de J. A; GUARIENTI, E. M.; FONTANELI, R. S.; ZANOTTO, D. L. Influência de cortes simulando pastejo na composição química de grãos de cereais de inverno. Pesquisa Agropecuária Brasileira, Brasília, v. 34, n. 9, p. 1607-1614, set. 1999.

FEROLLA, F. S.; VÁSQUEZ, H. M.; SILVA, J. F. C.; VIANA, A. P.; DOMINGUES, F. N.; AGUIAR, R. S. Produção de matéria seca, composição da massa de forragem e relação lâmina foliar/caule + bainha de aveiapreta e triticale nos sistemas de corte e pastejo. Revista Brasileira de Zootecnia, Viçosa, MG, v. 36, n. 5, p. 15121517, 2007. Suplemento.

FONTANELI, R. S.; FONTANELI, R. S.; SANTOS, H. P. dos; NASCIMENTO JUNIOR, A. do N.; MINELLA, E.; CAIERÃO, E. Rendimento e valor nutritivo de cereais de inverno de duplo propósito: forragem verde e silagem ou grãos. Revista Brasileira de Zootecnia, Viçosa, MG, v. 38, n. 11, p. 2116-2120, 2009.

GODOY, R.; BATISTA, L. A. R. Recomendações de cultivares de aveia forrageira para região de São CarlosSP. São Carlos: EMBRAPA-UEPAE, 1990. 6 p.

GOMAR, E. P.; REICHERT, J. M.; REINERT, D. J.; PRECHAC, F. G.; BERRETA, E.; MARCHESI, O.; Semeadura direta de forrageiras de estação fria em campo natural com aplicação de herbicidas: I. Produção de forragem e contribuição relativa das espécies. Ciência Rural, Santa Maria, v. 34, n. 3, p. 761-767, 2004. 
INSTITUTO NACIONAL DE METEOROLOGIA - INMET. 2010. Disponível em: <http://www.inmet. gov.br/portal/index.php?r=home/page\&page $=$ rede_ estacoes auto graf $>$. Acesso em: 05 set. 2012.

KIRCHNER, R.; SOARES, A. B.; SARTOR, L. R; ADAMI, P. F.; MIGLIORINI, F.; FONSECA, L.; Desempenho de forrageiras hibernais sob distintos níveis de luminosidade. Revista Brasileira de Zootecnia, Viçosa, MG, v. 39, n. 11, p. 2371-2379, 2010.

LENZI, A. Desempenho animal e produção de forragem em dois sistemas de uso da pastagem: pastejo contínuo $\&$ pastoreio racional voisin. 2003. Dissertação (Mestrado em Agroecossistemas) - Universidade Federal de Santa Catarina, Florianópolis.

MACARI, S.; ROCHA, M. G. da; RESTLE, J.; PILAU, A.; FREITAS, F. K. de; NEVES, F.P. Avaliação da mistura de cultivares de aveia preta (Avena strigosa Schreb) com azevém (Lolium multiflorum Lam.) sob pastejo. Ciência Rural, Santa Maria, v. 36, n. 3, p. 910-915, maio/jun. 2006.

MEINERZ, G. R.; OLIVO, C. J.; FONTANELI, R. S.; AGNOLIN, C. A.; FONTANELLI, R. S.; HORST, T.; VIÉGAS, J.; BEM, C. M. de. Valor nutritivo da forragem de genótipos de cereais de inverno de duplo propósito. Revista Brasileira de Zootecnia, Viçosa, MG, v. 40, n. 6 , p. 1173-1180, 2011.

MOREIRA, A. L.; REIS, R. A.; SIMILI, F. F.; PEDREIRA, M. S.; CONTATO, E. D.; RUGGIERI, A. C. Época de sobressemeadura de gramíneas anuais de inverno e de verão no capim-tifton 85: produção e composição botânica. Ciência e Agrotecnologia, Lavras, v. 30, n. 4, p. 739-745, 2006.

NOLLER, C. H.; NASCIMENTO JUNIOR, D.; QUEIROZ, D. S. Exigências nutricionais de animais em pastejo. In: SIMPÓSIO SOBRE MANEJO DE PASTAGEM, 13., Piracicaba, 1996. Anais... Piracicaba: FEALQ, 1996. p. 151-184.

NORO, G.; SIMONE, N. S. B.; FONTANELI, R. S.; ANDREATTA, E. Gramíneas anuais de inverno para produção de forragem: avaliação preliminar de cultivares. Revista Brasileira Agrociência, Pelotas, v. 7, n. 1, p. 3540, 2003.
OLIVO, C. J.; MEINERZ, G. R.; AGNOLIN, C. A.; STEINWANDTER, E.; ZIECH, M. F.; SKONIESKI, F. R. Produção de forragem e carga animal de pastagens de Coastcross sobressemeadas com forrageiras de inverno. Revista Brasileira de Zootecnia, Viçosa, MG, v. 39, n. 1, p. 68-73, 2010.

OMETTO, J. C. Bioclimatologia vegetal. São Paulo: Ceres, 1981. 400 p.

PEREIRA, V. A.; MITTELMANN, A.; LEDO, F. J. S.; SOBRINHO, F. S.; AUAD, A. M.; OLIVEIRA, J. S. e. Comportamento agronômico de populações de azevém anual (Lolium multiflorum L.) para cultivo invernal na região sudeste. Ciência Agrotécnica, Lavras, v. 32, n. 2, p. 567-572, 2008.

PIN, E. A.; SOARES, A. B.; POSSENTI, J. C.; FERRAZZA, J. M. Forage production dynamics of winter annual grasses sown on different dates. Revista Brasileira de Zootecnia, Viçosa, MG, v. 40, n. 3, p. 509$517,2011$.

PRADO, I. N. do; MOREIRA, F. B.; CECATO, U.; YOSHIMI WADA, F.; OLIVEIRA, E. de; REGO, F. C. de A. Sistemas para crescimento e terminação de bovinos de corte a pasto: Avaliação do desempenho animal e características da forragem. Revista Brasileira de Zootecnia, Viçosa, MG, v. 32, n. 4, p. 955-965, 2003.

PRIMAVESI, A. C.; PRIMAVESI, O.; CANTARELLA, H.; GODOY, R. Resposta da aveia branca à adubação em Latossolo vermelho-amarelo em dois sistemas de plantio. Revista Brasileira de Zootecnia, Viçosa, MG, v. 33, n. 1, p. 79-86, 2004.

ROCHA, M. G.; PEREIRA, L. E. T.; SCARAVELLI, L. F. B.; OLIVO, C. J.; AGNOLIN, C. A.; ZIECH, M. F. Produção e qualidade de forragem da mistura de aveia e azevém sob dois métodos de estabelecimento. Revista Brasileira de Zootecnia, Viçosa, MG, v. 36, n. 1, p. 7-15, 2007.

RODRIGUES, A. de A.; MENDONÇA, F.C.; PEDROSO, A. de F.; SANTOS, P. M.; FREITAS, A. R. de; TUPY, O. Utilização, em pastejo, de aveia semeada sobre capimTanzania, para complementação da dieta de vacas de alta produção na época da seca: resposta bioeconômica. São Carlos: Embrapa Pecuária Sudeste, 2006. (Boletim de Pesquisa e Desenvolvimento, 3). 